\title{
Serum indoleamine 2,3-dioxygenase activity is associated with reduced immunogenicity following vaccination with MVA85A
}

Rachel Tanner ${ }^{1}$, Kristina Kakalacheva ${ }^{1,2}$, Ellen Miller ${ }^{1,3}$, Ansar A Pathan ${ }^{1,4}$, Rod Chalk ${ }^{5}$, Clare R Sander ${ }^{1,6}$, Tom Scriba $^{7}$, Michelle Tameris ${ }^{7}$, Tony Hawkridge ${ }^{7,9}$, Hassan Mahomed ${ }^{7,10,11}$, Greg Hussey ${ }^{7,9}$, Willem Hanekom ${ }^{7}$, Anna Checkley ${ }^{1,8}$, Helen McShane ${ }^{1}$ and Helen A Fletcher ${ }^{1,8^{*}}$

\begin{abstract}
Background: There is an urgent need for improved vaccines to protect against tuberculosis. The currently available vaccine Bacille Calmette-Guerin (BCG) has varying immunogenicity and efficacy across different populations for reasons not clearly understood. MVA85A is a modified vaccinia virus expressing antigen $85 \mathrm{~A}$ from Mycobacterium tuberculosis which has been in clinical development since 2002 as a candidate vaccine to boost BCG-induced protection. A recent efficacy trial in South African infants failed to demonstrate enhancement of protection over BCG alone. The immunogenicity was lower than that seen in UK trials.

The enzyme Indoleamine 2,3-dioxygenase (IDO) catalyses the first and rate-limiting step in the breakdown of the essential amino acid tryptophan. T cells are dependent on tryptophan and IDO activity suppresses T-cell proliferation and function.

Methods: Using samples collected during phase I trials with MVA85A across the UK and South Africa we have investigated the relationship between vaccine immunogenicity and IDO using IFN- $\gamma$ ELISPOT, qPCR and liquid chromatography mass spectrometry.
\end{abstract}

Results: We demonstrate an IFN- $\gamma$ dependent increase in IDO mRNA expression in peripheral blood mononuclear cells (PBMC) following MVA85A vaccination in UK subjects. IDO mRNA correlates positively with the IFN- $\gamma$ ELISPOT response indicating that vaccine specific induction of IDO in PBMC is unlikely to limit the development of vaccine specific immunity. IDO activity in the serum of volunteers from the UK and South Africa was also assessed. There was no change in serum IDO activity following MVA85A vaccination. However, we observed higher baseline IDO activity in South African volunteers when compared to UK volunteers. In both UK and South African serum samples, baseline IDO activity negatively correlated with vaccine-specific IFN- $\gamma$ responses, suggesting that IDO activity may impair the generation of a CD4+ T cell memory response.

Conclusions: Baseline IDO activity was higher in South African volunteers when compared to UK volunteers, which may represent a potential mechanism for the observed variation in vaccine immunogenicity in South African and UK populations and may have important implications for future vaccination strategies.

Trial registration: Trials are registered at ClinicalTrials.gov; UK cohort NCT00427830, UK LTBI cohort NCT00456183, South African cohort NCT00460590, South African LTBI cohort NCT00480558.

Keywords: Indoleamine 2,3-dioxygenase, Tryptophan, Kynurenine, Tuberculosis, Vaccine, MVA85A, BCG, Interferon- $\gamma$, LC-MS

\footnotetext{
* Correspondence: helen.fletcher@lshtm.ac.uk

${ }^{1}$ The Jenner Institute, University of Oxford, Oxford, UK

${ }^{8}$ Present address: London School of Hygiene and Tropical Medicine, Keppel

Street, London, UK

Full list of author information is available at the end of the article
}

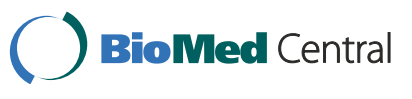

(c) 2014 Tanner et al.; licensee BioMed Central Ltd. This is an Open Access article distributed under the terms of the Creative Commons Attribution License (http://creativecommons.org/licenses/by/4.0), which permits unrestricted use, distribution, and reproduction in any medium, provided the original work is properly credited. The Creative Commons Public Domain Dedication waiver (http://creativecommons.org/publicdomain/zero/1.0/) applies to the data made available in this article, unless otherwise stated. 


\section{Background}

Tuberculosis (TB) poses an increasing global health threat, with about 10 million new cases and 1.7 million deaths annually (WHO Global Tuberculosis report) [1]. Most of the global TB burden is borne by the developing world, with $86 \%$ of cases occurring in South-East Asia, Africa and the Western Pacific. With the emergence of multi-drug resistant strains of Mycobacterium tuberculosis (MTB) and the spread of HIV, there is an even greater need for an improved vaccine. Mycobacterium bovis Bacille CalmetteGuerin (BCG) is the only vaccine currently available against TB. Although BCG confers reliable protection against disseminated TB during childhood $[2,3]$, protection against adult pulmonary disease varies considerably with geographical location [4].

A similar population-dependent variability in vaccine immunogenicity has been noted with several other vaccines [5-7]. Here we report lower vaccine-specific IFN- $\gamma$ ELISPOT responses in South African adults when compared with UK adult volunteers following administration of the TB vaccine candidate MVA85A. MVA85A is a recombinant strain of modified vaccinia virus Ankara expressing the immunodominant mycobacterial antigen 85A (Ag85A) from MTB. MVA85A has proven to be both safe and immunogenic [8-11]. However, in a recent phase IIb efficacy trial in South African infants immunogenicity was modest and there was no significant protection from clinical disease [11]. In this study we have investigated the relationship between vaccine immunogenicity and the enzyme Indoleamine 2,3-dioxygenase (IDO) in different populations.

IDO catalyses the first and rate-limiting step in the breakdown of the essential amino acid tryptophan (L-Trp) into kynurenine (L-Kyn) and other downstream metabolites [12]. IDO is expressed intracellularly in a constitutive or inducible manner in most non-hepatic cell types, predominantly in the lungs and placenta [13]. Induction is seen in response to various stimuli including IFN- $\alpha / \beta$ and bacterial lipopolysaccharide, but the most potent inducer is gamma interferon (IFN- $\gamma$ ) [14,15].

Since it was established that IDO is instrumental in the maintenance of maternal-foetal tolerance by T-cell suppression [16], there has been a growing body of research on its immunoregulatory effects. L-Kyn and other catabolites produced through the action of IDO have been implicated in the suppression of T-cell proliferation and induction of apoptosis [17,18]. Furthermore, IDO expression has been shown to induce regulatory $\mathrm{T}$ cells [19] and inhibit natural killer cells [20].

We hypothesised that levels of IDO may be relevant to MVA85A vaccine immunogenicity as several studies have indicated a role for the enzyme in mycobacterial infection and disease [21,22]. IDO activity in mice increases following MTB infection in an IFN- $\gamma$ dependent manner [15]. Furthermore, IDO is important in protection of the granuloma from T-cell attack [23], and is induced following BCG vaccination in mice [24]. It was anticipated that IDO expression and activity might similarly be increased following vaccination with MVA85A.

We demonstrate an IFN- $\gamma$ dependent increase in IDO mRNA expression in PBMC following MVA85A vaccination. IDO mRNA correlates positively with the IFN- $\gamma$ ELISPOT response indicating that vaccine specific induction of IDO in PBMC is unlikely to limit the development of antigen specific immunity.

IDO activity in the serum of volunteers from the UK and South Africa was also assessed. There was no change in serum IDO activity following vaccination with MVA85A. However, we saw higher baseline IDO activity in South African volunteers when compared to UK volunteers. This higher IDO activity was unlikely due to latent TB infection as IDO activity was lower in both latently TB infected (LTBI) and uninfected UK adults when compared to South African adults. In both UK and South African adults, baseline serum IDO activity negatively correlated with vaccine-specific IFN- $\gamma$ responses. The strongest correlation was observed between serum IDO at baseline and the magnitude of the ELISPOT response 6 months following immunisation, indicating that IDO activity may impair the generation of a CD4+ T cell memory response.

\section{Methods}

\section{Ethics statement}

UK participants were recruited under protocols approved by the Oxfordshire Research Ethics Committee (OxREC). South African participants were recruited under a protocol approved by the Medicines Control Council of South Africa, the Human Research Ethics Committees of the University of Cape Town (Cape Town, South Africa) and the Oxfordshire Research Ethics Committee (OxREC). Written informed consent was obtained from all individuals prior to enrolment in the trials. Trials were conducted according to the International Conference on Harmonization - Good Clinical Practice guidelines and are registered at ClinicalTrials.gov.

Peripheral blood mononuclear cells (PBMC) were isolated from buffy coats from healthy PPD positive donors (National Blood Service, Bristol), protocols approved by the Oxfordshire Research Ethics Committee (OxREC).

\section{Study design and participants}

All participants received $5 \times 10^{7}$ plaque forming units (PFU) of MVA85A (Table 1). Participants in all groups were 18 to 50 years of age and seronegative for HIV, hepatitis $\mathrm{B}$ and hepatitis $\mathrm{C}$ viruses. All participants were previously BCG vaccinated. 
Table 1 Demographics of study participants

\begin{tabular}{|c|c|c|c|c|}
\hline Trial registration number & NCT00427830 & NCT00456183 & NCT00460590 & NCT00480558 \\
\hline Country & UK & UK & South Africa & South Africa \\
\hline No of participants & 11 & 11 & 10 & 12 \\
\hline LTBI & - & + & - & + \\
\hline History of BCG & + & $+/-$ & $+/-$ & $+/-$ \\
\hline Dose of MVA85A & $5 \times 10^{7} \mathrm{PFU}$ & $5 \times 10^{7} \mathrm{PFU}$ & $5 \times 10^{7} \mathrm{PFU}$ & $5 \times 10^{7} \mathrm{PFU}$ \\
\hline Age, median (range) & $27(21-54)$ & $30.5(20-49)$ & $35.5(20.7-48.7)$ & $36(27-49)$ \\
\hline Gender, \% male & 39 & 83 & 33.3 & 75 \\
\hline serum samples available, week (number) & $0(10), 1(5), 4(8)$ & $0(10), 1(6), 4(10)$ & $0(10), 1(10)$ & - \\
\hline PBMC samples available, week (number) & $0(8), 1(9), 4(9)$ & - & - & - \\
\hline
\end{tabular}

Participants were either negative by ex vivo ELISPOT assay for ESAT-6 and CFP-10 or latently infected with MTB (LTBI). Volunteers in the LTBI groups were healthy adults, most of whom had been BCG vaccinated (Heaf test grade II-IV, TST induration $\geq 10 \mathrm{~mm}$ ) and LTBI was confirmed by an IFN- $\gamma$ ELISpot response to the M.tb specific antigens ESAT- 6 and CFP-10 of $>50$ SFC/million. Participants had normal chest radiographs and no clinical evidence of TB disease.

\section{Immunological assays}

Immune responses were measured by ex vivo IFN- $\gamma$ ELISPOT assay with freshly isolated PBMC as previously described [9]. PBMC $\left(0.3 \times 10^{6}\right.$ per well $)$ were cultured for 18 hours with 8 pools of Ag85A peptides $(10 \mu \mathrm{g} / \mathrm{ml}$ each peptide) overlapping by 10 amino acids (Pathan [25]). The Ag85A peptide specific IFN- $\gamma$ ELISPOT data used in this study has been previously reported by others $[8-10,26]$.

\section{Cell culture}

For the measurement of IDO mRNA expression $5 \times 10^{5}$ freshly thawed PBMCs from trial volunteers were stimulated for 16 hours with $85 \mathrm{~A}$ peptides or media alone. For blocking experiments $\mathrm{PBMC}$ were cultured with or without the addition of $10 \mu \mathrm{g} / \mathrm{ml}$ anti-IFN- $\gamma$ or $10 \mu \mathrm{g} / \mathrm{ml}$ recombinant human IFN- $\gamma$ (BD Biosciences). CD14+ cells were depleted from buffy coat PBMC from PPD+ donors using CD14 labeled magnetic beads (Invitrogen).

\section{IDO mRNA quantification by real time PCR}

Half a million freshly thawed PBMCs from trial volunteers were stimulated for 16 hours with Ag85A peptides or media alone. Cells were then pelleted and RNA extracted using the RNeasy Minikit (Qiagen) according to the manufacturer's instructions. Reverse transcription reaction was performed immediately following extraction with $10 \mu \mathrm{l}$ of RNA extract using oligo-dT (Eurofins MWG Operon) and the Omniscript Kit (Qiagen). RNase inhibitor, $10 \mathrm{U} / \mu \mathrm{l}$, (Applied Biosciences) was added to the reactions, which were then incubated for 60 minutes at $37^{\circ} \mathrm{C}$. Quantitative PCR (qPCR) was performed with $1 \mu \mathrm{l}$ of cDNA using QuantiTect mastermix (Qiagen) and $10 \mathrm{pmol} / \mu \mathrm{l}$ of the respective forward and reverse primers designed using PrimerQuest (Integrated DNA Technologies) and ordered from Eurofins MWG Operon. The designed primers were as follows:

\section{HPRT (F:TATGGACAGGACTGAACGTC and R:CTACAATGTGATGGCCTCCC) IDO (F:CTGCTGGTGGAGGACATG and R:CACAGGAAGTTCCTGTGAG)}

qPCR was performed using a Roche LightCycler 480 with the following cycling conditions: initial activation for 15 minutes at $95^{\circ} \mathrm{C}$ followed by 55 cycles of 15 seconds at $95^{\circ} \mathrm{C}, 20$ seconds at $60^{\circ} \mathrm{C}$, and 20 seconds at $72^{\circ} \mathrm{C}$. PCR products of known concentrations $\left(10^{6}\right.$ to $10^{1}$ mRNA copies) were used for the generation of a standard curve for each PCR plate. Analysis was performed with Roche LightCycler 480 software and Ct values were used for conversion to mRNA copy number according to the standard curves. Melting curves were calculated to exclude non-specific binding or primer-dimer formation.

\section{Liquid chromatography-mass spectrometry}

For the measurement of serum IDO activity $5 \mu \mathrm{l} 0.1 \%$ formic acid (Sigma Aldrich) containing $30 \mu \mathrm{g} / \mathrm{ml}$ of the internal standard L-Trp-(indole- $\left.\mathrm{d}_{5}\right)\left(\mathrm{d}_{5}\right.$-Trp) (GK Gas Products Ltd) was added to $100 \mu \mathrm{l}$ participant serum, and incubated with $140 \mu \mathrm{l}$ acetonitrile and $160 \mu \mathrm{l}$ methanol (both Fisher Scientific) for 20 minutes at $-20^{\circ} \mathrm{C}$. Samples were then centrifuged at $14000 \mathrm{~g}$ for 10 minutes at $4^{\circ} \mathrm{C}$ and the supernatant removed and vacuum dried. The lyophilised samples were re-suspended in $52.5 \mu \mathrm{l}$ $0.1 \%$ formic acid and centrifuge filtered at $14000 \mathrm{~g}$ for 30 minutes at $4^{\circ} \mathrm{C}(10 \mathrm{kDa}$ microcentrifuge filter, Millipore). The filtrate was transferred to $0.3 \mathrm{ml}$ autosampler vials for analysis. A set of four mixed standards was prepared in $0.1 \%$ formic acid using twofold serial dilutions of L-Trp $(50 \mu \mathrm{g} / \mathrm{ml})$ and L-Kyn $(2.5 \mu \mathrm{g} / \mathrm{ml})$ (both Sigma- 
Aldrich), and containing $2 \mu \mathrm{g} / \mathrm{ml}$ of the $\mathrm{d}_{5}$-Trp internal standard. External standards were run every 10 samples and four-point calibration curves constructed for each set of samples using the mean values from multiple readings across that trial.

Samples were injected into an Acclaim Pepmap 100 c18 $1.0 \mathrm{~mm} \times 150.0 \mathrm{~mm}$ column (Thermo) using an Ultimate 3000 nano HPLC pump (Dionex) to generate a post-split flow rate of $3 \mu \mathrm{l} / \mathrm{min}$. For the first 3.5 minutes, the mobile phase was held at $2 \%$ acetonitrile in $2 \%$ aqueous formic acid (A). A second solvent mixture (B) containing $2 \%$ formic acid in acetonitrile was added, increasing gradually in percentage until 17.5 minutes, when it was held at $80 \%$ for 7 minutes at a flow rate of $3 \mu \mathrm{l} / \mathrm{min}$ for the separation. The column eluent was directed to the electrospray ion source of a HCT Ultra ion trap mass spectrometer (capillary $4 \mathrm{kV}$, skimmer $40 \mathrm{~V}$, desolvation $300^{\circ} \mathrm{C}$, nebulizer $10 \mathrm{psi}$, drying gas $5 \mathrm{l} / \mathrm{min}$ ) (Bruker Daltonics). The helium collision gas was at $4 \times 10^{-6}$ Bar, and spectra were acquired in multiple reaction monitoring mode. For the measurement of L-Trp and L-Kyn, the $m / z 205$ and $m / z 209$ precursor ions respectively were selected and fragmented at an amplitude of 1.0 (arbitrary units) to produce monitored product ions at $m / z 188$ for L-Trp and $m / z 192.2$ for L-Kyn. For the measurement of the internal standard $\mathrm{d}_{5}$-Trp, the $m / z 210$ precursor ion was isolated and fragmented, producing a product ion at $m / z$ 192.1, which was then further fragmented to produce a monitored product ion at $m / z$ 150. The complete cycle time was 32.2 minutes. The relative abundance of L-Trp and L-Kyn in the samples was calculated by dividing the MS peak area of the monitored ion by the peak area of the internal standard and converted to a concentration using the external standard curves.

\section{Statistical analysis}

The Mann-Whitney test was used for comparison of median values between groups for IDO mRNA expression. The Wilcoxon Signed-Rank test was used for comparisons of IDO activity between time points, and twotailed Spearman's Rank Correlation analyses were used to identify correlations between IDO mRNA, IDO activity and fresh IFN- $\gamma$ ELISPOT data gathered at the time of the clinical trials. $p<0.05$ was considered to be statistically significant. Analysis was performed using the software Prism 5 (GraphPad Software Inc, CA) and SPSS 20.0 for Windows (SPSS Inc, Chicago, IL).

\section{Results}

MVA85A shows reduced immunogenicity in South African adults

We have previously shown that the immunogenicity to MVA85A is not altered by LTBI status within a population, either UK or South African [10,26]. Data from non-LTBI and LTBI UK populations was therefore combined in to one UK cohort $(n=22)$ and compared with one combined South African cohort $(n=22)$. Antigen specific IFN- $\gamma$ ELISPOT responses to Ag85A overlapping peptide pools were measured $0-24$ weeks following vaccination with MVA85A. Immune responses were significantly lower in South African adults at weeks 1, 4 and 24 following vaccination with MVA85A (Mann Whitney Test $\mathrm{P}<0.05$ or $\mathrm{P}<0.005$ ) (Figure $1 \mathrm{~A}$ ). All adults had a history of BCG vaccination and there was an equivalent proportion of LTBI in each cohort (Table 1).

The total immune response following vaccination with MVA85A is lower in South Africa when compared to the UK. Area under the curve (AUC) of the IFN- $\gamma$ ELISPOT response to Ag85A peptides from 0-24 weeks was calculated for each volunteer and AUC values for each volunteer were plotted by group. The median AUC response was significantly lower in South Africa when compared to the UK (Mann Whitney Test $\mathrm{P}<0.05$ ) (Figure 1B).

\section{IDO mRNA production correlates with IFN- $\gamma$ response to MVA85A in UK adults, is produced by CD14+ monocytes following vaccination with MVA85A and is dependent on IFN- $\gamma$}

We performed quantitative real time PCR analysis to measure the expression of IDO mRNA in PBMC from MVA85A vaccinated adults. PBMC from UK subjects vaccinated with MVA85A were cultured with Ag85A peptides or media only and the fold increase in IDO mRNA expression over time was determined for each subject. Ag85A-induced IDO mRNA expression was significantly greater at weeks 1 and 4 when compared to week 0 (Wilcoxon $\mathrm{P}<0.05$ ) (Figure 2A).

The increase in IDO mRNA expression correlated positively with the magnitude of the IFN- $\gamma$ ELISPOT response following vaccination with MVA85A (Figure 2B). The peak induction of IDO mRNA was observed 4 weeks following immunisation with MVA85A. PBMC isolated 4 weeks following MVA85A vaccination were cultured with recombinant human (rh) IFN- $\gamma$, Ag85A peptides or Ag85A peptides and anti-IFN- $\gamma$ antibodies and the fold change in expression in stimulated compared to unstimulated PBMC was determined. Recombinant human IFN- $\gamma$ and Ag85A peptide stimulation induced the expression of IDO mRNA. Co-culturing cells with Ag85A peptides and anti-IFN- $\gamma$ antibodies resulted in a significant reduction of Ag85A specific IDO mRNA expression (Figure 2C). CD14+ magnetic beads were used to deplete monocytes from the PBMC of 5 PPD positive donors. IDO expression was enriched in the CD14+ fraction and depleted when CD14+ cells were removed indicating that CD14+ monocytes are a major source of IDO 


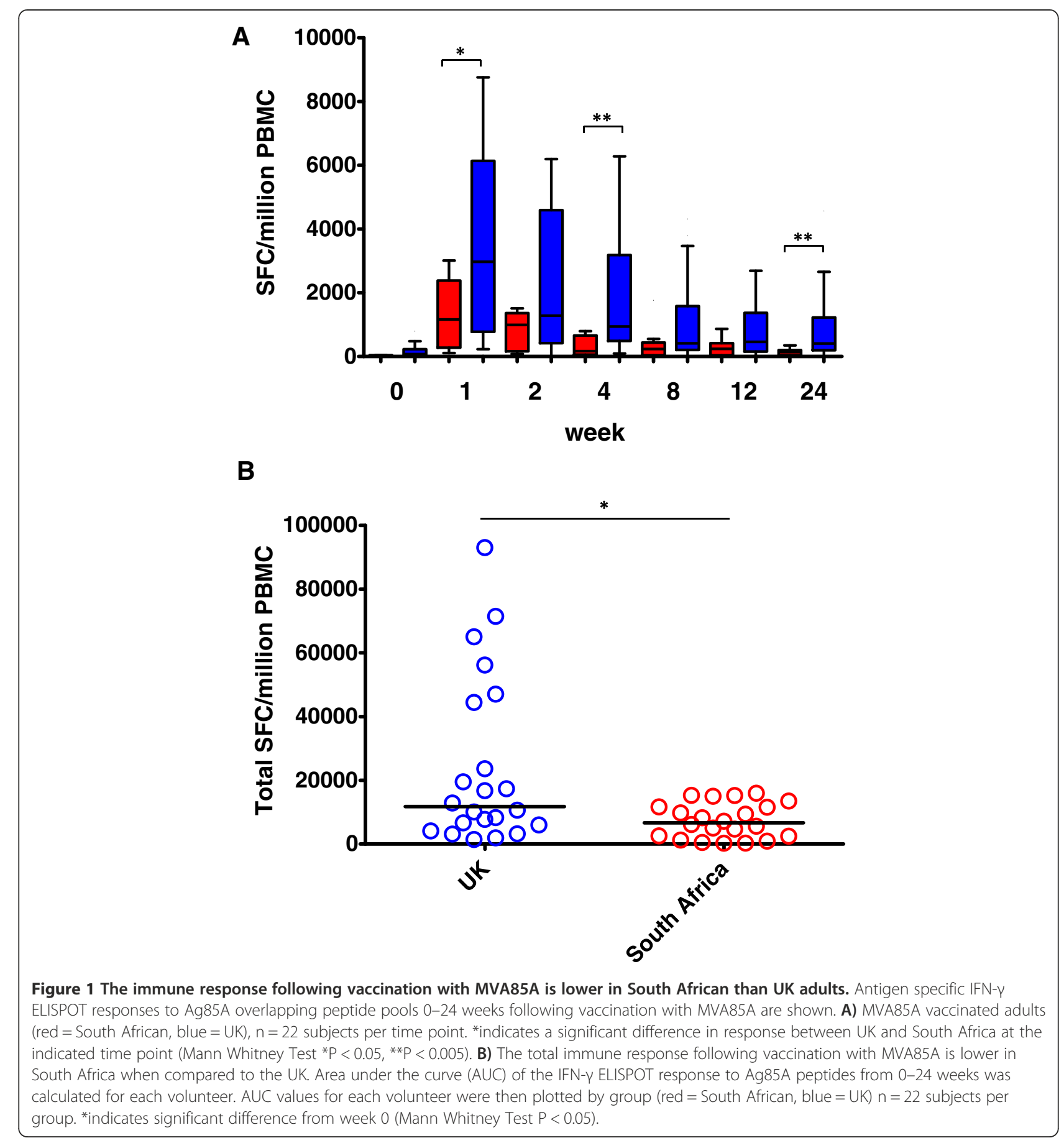

mRNA production in PBMC cultured with mycobacterial antigens (Figure 2D).

IDO activity in serum at baseline is higher in South African than UK volunteers

We used LC-MS to determine L-Trp and L-Kyn levels in the stored sera of UK and South African adults. For the UK volunteers, assays were performed on samples from baseline (pre-vaccination), and weeks 1, 2 and 4 post-vaccination. For the South African group, serum was only available from baseline (pre-vaccination) and week 1 post-vaccination. IDO activity was calculated as the ratio of L-Kyn to L-Trp (Figure 3A). There were no statistically significant differences in levels of L-Trp, L-Kyn or IDO activity pre- and post-vaccination in any individual group, or when all data was combined (Figure 3B). Although there was no vaccine related change in IDO activity, the baseline serum IDO activity in South African 
A
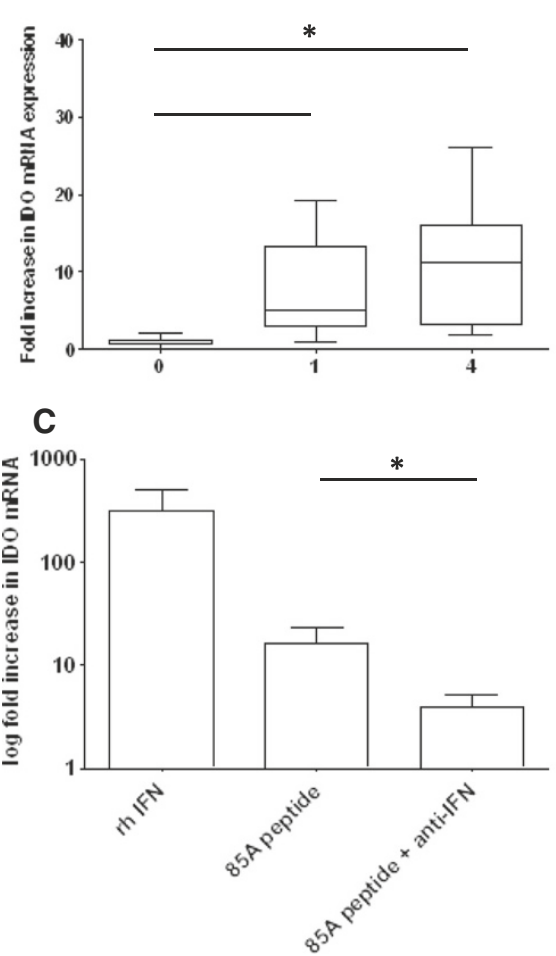

B

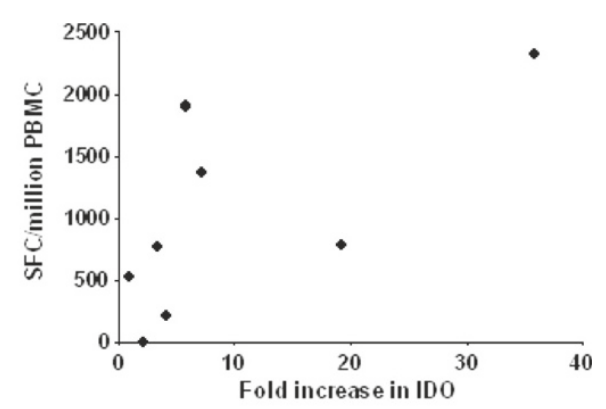

D

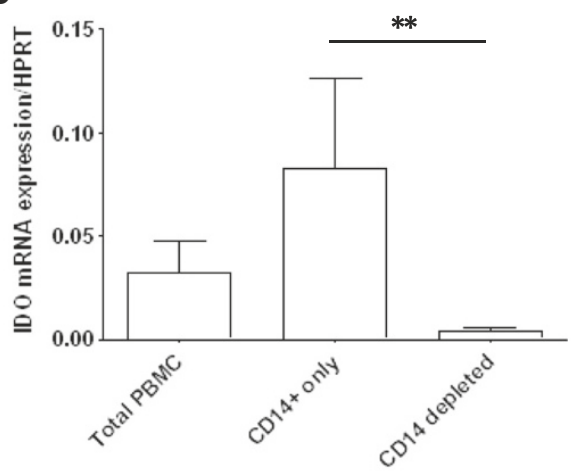

Figure 2 IDO mRNA following MVA85A vaccination is produced by CD14+ monocytes and dependent on IFN- $\gamma$ stimulation. A) PBMC from BCG vaccinated subjects boosted with MVA85A were cultured with 85A peptides or media only and the fold increase in IDO mRNA expression over time was determined for each subject $(n=8)$. Ag85A-induced IDO mRNA expression was significantly greater at weeks 1 and 4 when compared to week 0 (Wilcoxon * $<<.05)$. B) The increase in IDO mRNA expression correlated with the IFN-y ELISPOT response (data from week 1 following MVA85A) (Spearman's correlation $P<.05, r=0.79$ ). C) PBMC from BCG vaccinated subjects boosted 4 weeks previously with MVA85A were cultured with recombinant human (rh) IFN- $\gamma$, 85A peptides or 85A peptides and anti-IFN- $\gamma$ antibodies and the fold change in expression in stimulated compared to unstimulated PBMC was determined $(n=5)$. Recombinant human IFN- $\gamma$ and $85 A$ peptide stimulation induced the expression of IDO mRNA. Co-culturing cells with 85A peptides and anti-IFN- $\gamma$ antibodies resulted in significant reduction of $85 \mathrm{~A}$ specific IDO mRNA expression (Wilcoxon ${ }^{*} P<.05$ ). D) CD14+ magnetic beads were used to deplete monocytes from total PBMC. IDO expression was enriched in the CD14+ fraction and depleted when CD14+ cells were removed $(n=5)$. Mann Whitney was used for comparison between groups (**P $<.005)$.

volunteers was higher than that of the UK volunteers $(p=<.05$, Mann Whitney) (Figure 3B).

\section{IDO activity in serum is negatively correlated with the magnitude of the IFN- $\gamma$ ELISPOT response following vaccination with MVA85A}

We correlated IDO activity in serum with ex vivo 85A peptide specific IFN- $\gamma$ ELISPOT responses. In both UK and South African populations IDO activity in the serum was negatively correlated with IFN- $\gamma$ ELISPOT responses with the strongest correlations seen with IFN- $\gamma$ ELISPOT responses measured at 4 and 24 weeks $(\mathrm{p}<.05$ and $\mathrm{P}<.005$, Spearman's) (Figure $4 \mathrm{~A}$ and $\mathrm{B}$ ). The relationship between serum IDO activity and the long term ELISPOT response suggests that serum IDO activity may impair the development of a long-term, $\mathrm{T}$ cell memory response to Ag85A.

\section{Discussion}

Immune responses to MVA85A were higher in UK adults than South African adults regardless of LTBI status. There was a similar age and gender distribution among the cohorts and all adults were screened to be seronegative for HIV, hepatitis B and hepatitis C. We have previously shown that TGF- $\beta 1$, regulatory T-cells and TLR- 1 expression are correlated with the magnitude of the T-cell response to MVA85A in UK adults [27-29]. In this study we have investigated the relationship between vaccine immunogenicity and the enzyme IDO. As MVA85Ax induces potent IFN- $\gamma$ responses [9], we hypothesised that IDO mRNA would be increased following MVA85A vaccination. In UK adults we observed an increase in IDO mRNA expression at weeks 1 and 4 post-vaccination compared to baseline. IDO mRNA was induced by IFN- $\gamma$ in CD14+ cells following stimulation of PBMC with Ag85A 
A

L-Trp, L-Kyn, d5-Trp (100 $\mu g / \mathrm{ml}$ each) direct infusion

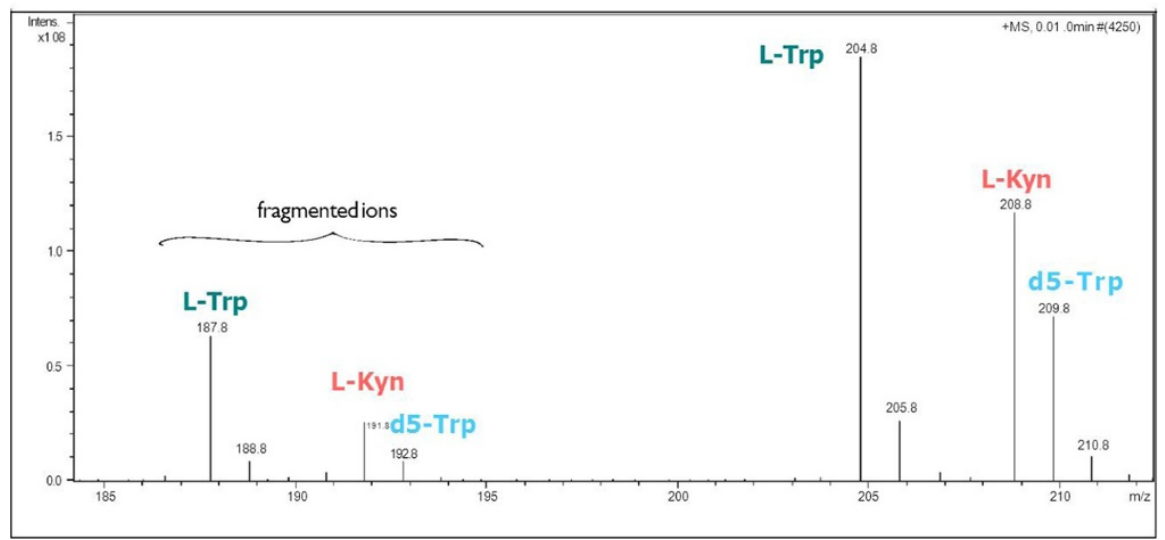

B

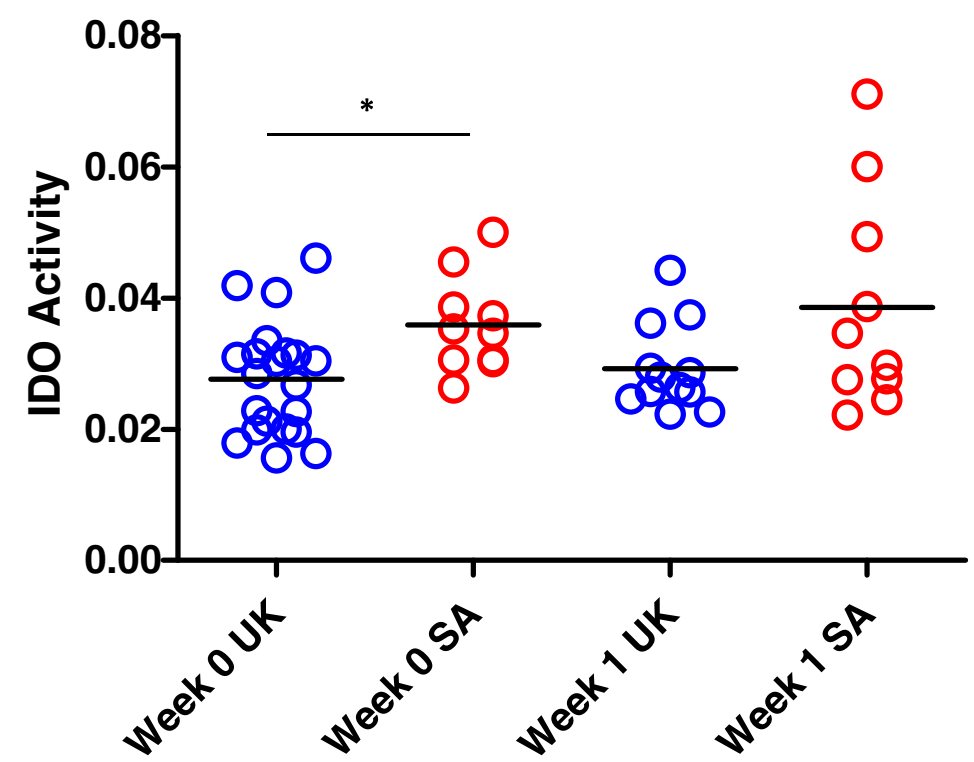

Figure 3 Serum IDO activity is higher in South African compared to UK adults. A) Serum IDO activity was measured in serum using LC-MS to quantity L-Trp and L-Kyn in participant serum. The ratio of L-Trp/L-Kyn gives a measure of IDO enzyme activity in host serum. B) IDO activity was assessed in serum from UK and South African adults at baseline (pre-vaccination, week 0) and 1 week following immunisation with MVA85A. Mann Whitney was used for comparison between groups ( $\left.{ }^{*} \mathrm{P}<.05\right)$.

peptides. To determine if IDO in PBMC could limit the magnitude of the immune response to MVA85A we correlated the increase in IDO mRNA with the Ag85A peptide specific IFN- $\gamma$ ELISPOT response. IDO mRNA increase correlated positively with the IFN- $\gamma$ ELISPOT response, suggesting that following vaccination with MVA85A, IDO from CD14+ cells does not limit the secretion of IFN- $\gamma$ from T-cells.

We then went on to investigate IDO activity in the serum of UK and South African adults using LC-MS. IDO activity in the serum did not change following vaccination with MVA85A, which may be a result of the transient effect of the vaccine; the MVA vector is non-replicating and does not persist in the host and systemic effects are usually undetectable $24-48$ hours after immunisation $[13,25]$.

Although we did not observe a change in serum IDO activity due to vaccination we did see higher baseline IDO activity in the serum of South African adults compared with adults from the UK. This higher IDO activity was unlikely to be due to latent TB infection as IDO activity was lower in both LTBI and uninfected UK adults when compared to South African adults. Active TB patients have increased activity of serum IDO [22], 


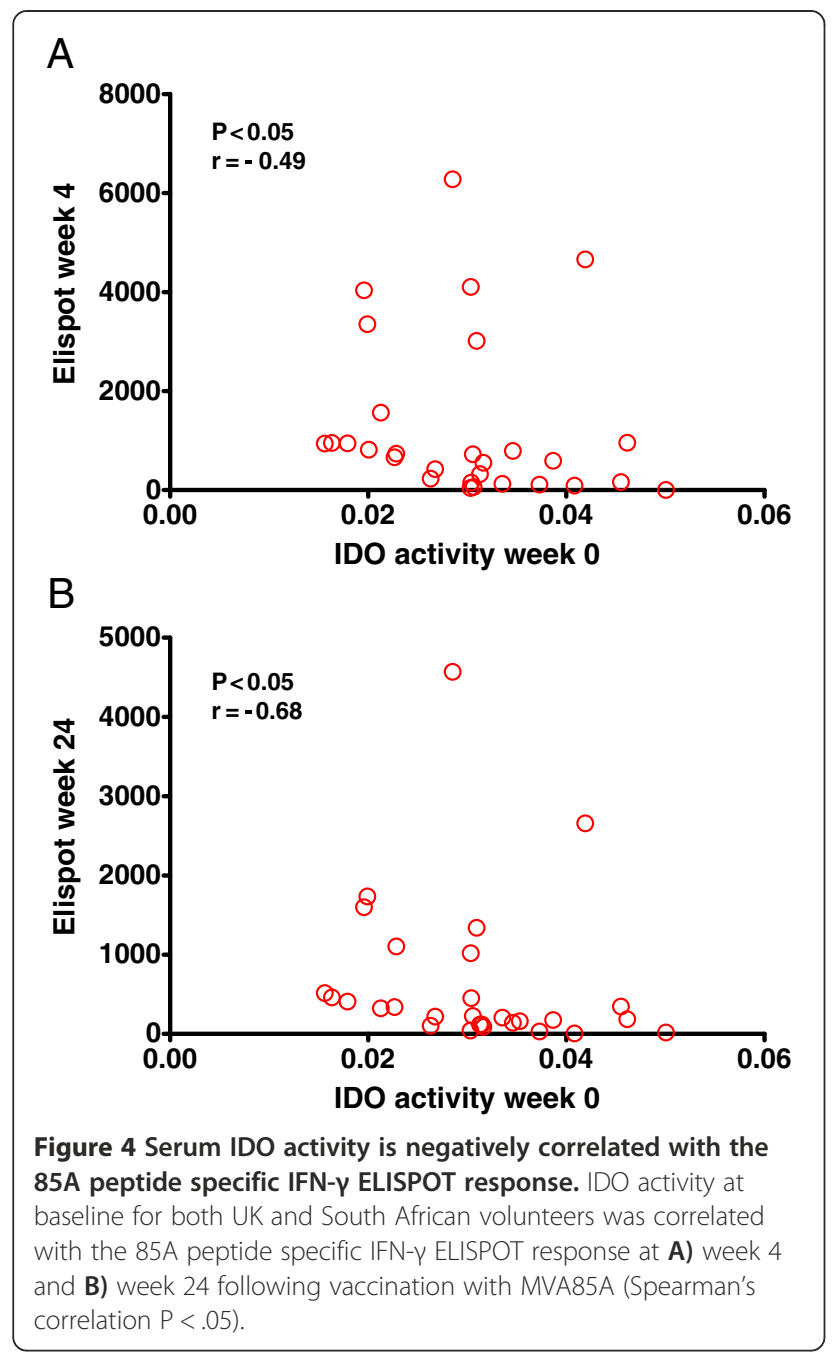

however, we saw no difference in IDO activity by LTBI status, indicating that IFN- $\gamma$ secretion in response to ESAT-6 and CFP-10 (used here to define LTBI) does not necessarily reflect chronic exposure to MTB or that the exposure is below the threshold required to see a change in systemic IDO activity.

In addition to $\mathrm{TB}$ there are other chronic infectious and non-infectious diseases which stimulate the production of IFN- $\gamma$ and could induce IDO activity. In a recent study of the yellow fever vaccine YF-17D in volunteers from Uganda and Switzerland, Ugandan volunteers demonstrated higher frequencies of exhausted and activated NK cells, differentiated $\mathrm{T}$ and $\mathrm{B}$ cells, and proinflammatory monocytes at baseline, indicating immune activation [30]. Furthermore, a study of Malawian and UK adolescents showed that Malawian volunteers had a lower percentage of naïve $\mathrm{T}$ cells and higher percentage of antigen-experienced $\mathrm{T}$ cells and CMV seroprevalence compared with age-matched UK volunteers. The authors conclude that this difference is likely to reflect a greater natural exposure to various infections in the African environment [31]. It may be that a similar effect present in South African volunteers results in constitutively higher levels of IDO activity.

We investigated the relationship between serum IDO activity and the MVA85A vaccine-specific IFN- $\gamma$ ELISPOT response. Higher IDO activity at the time of MVA85A vaccination is correlated with lower vaccine specific IFN- $\gamma$ T-cell responses at both 4 and 24 weeks following immunisation, and these are also the time points at which we see the greatest difference in immune response between UK and South African adults (Figure 1). Although the peak effector response to MVA85A is observed 1 week following immunisation, the peak proliferative response is seen at week 24 [32]. IDO has been shown to inhibit both $\mathrm{T}$ cell proliferation and the generation of a $\mathrm{T}$ cell memory response and it is the longer-term memory response to MVA85A which is most correlated with IDO activity in the serum $[17,33]$. In the yellow fever vaccine study described above, Ugandan volunteers showed an impaired vaccine response compared with Swiss volunteers, and this was associated with measures of immune activation at baseline [30].

It is possible that variation in serum IDO activity between populations may also account for variations in the immunogenicity and efficacy of BCG and other T-cell inducing vaccines. Manipulation of this pathway could thus be used to improve vaccine efficacy in endemic countries. There is currently interest in developing IDO inhibitors for the treatment of cancer which may have potential application in vaccination, in particular therapeutic vaccination, as TB patients have high levels of IDO activity. Another strategy is to target the IDO enzyme through boosting of naturally occurring T-cell responses directed against IDO epitopes [34] or silencing of the IDO gene [35].

\section{Conclusions}

Using serum and PBMC collected during a series of phase I trials with MVA85A we have shown that IDO activity in the serum is correlated with the magnitude of the immune response to MVA85A. High baseline IDO activity, possibly resulting from chronic immune activation, could act to reduce IFN- $\gamma$ ELISPOT responses by limiting $\mathrm{T}$ cell proliferation and the development of CD4+ T cell memory. The role of IDO-mediated suppression in vaccine induced immunity warrants further investigation.

\section{Abbreviations}

MTB: Mycobacterium tuberculosis; TB: Tuberculosis; LTBI: Latently MTB

infected; TST: Tuberculin skin test; BCG: Bacille Calmette-Guerin; MVA85A: Modified Vaccinia virus expressing antigen 85A from Mycobacterium tuberculosis; Ag: Antigen; UK: United Kingdom; IDO: Indoleamine 2,3-dioxygenase; L-Trp: Tryptophan; L-Kyn: Kynurenine; IFN-ү: Interferon-gamma; PBMC: Peripheral blood mononuclear cells; 
mRNA: Messenger ribonucleic acid; ELISPOT: Enzyme-linked immunosorbent spot; PPD: Tuberculin purified protein derivative; ESAT-6: Early secreted antigenic target of 6 kDa; CFP-10: Culture filtrate protein 10; PFU: Plaque forming units; GPCR: Quantitative polymerase chain reaction; LC-MS: Liquid chromatography-mass spectrometry; HPLC: High-performance liquid chromatography; AUC: Area under the curve.

\section{Competing interests}

The authors have read the journal's policy and have the following conflicts: HM and AAP are named inventors in a patent filing related to MVA85A. There are no other conflicts of interest. These conflicts of interest will not in any way interfere with the authors' adherence to the journal's policies on sharing data and materials.

\section{Authors' contributions}

Conceived and designed the experiments: HF, RC, HMc, AC. Performed the experiments: RT, KK, EM, AC, AP, CS, TS, MT, TH, HM, GH, WH. Analysed the data: HF, RT, KK, EM, AC, HMC, AP, CS, TS, MT, TH, HM, GH, WH. Wrote the manuscript: HF, RT. All authors read and approved the final manuscript.

\section{Acknowledgements}

H.M. is a Wellcome Trust Senior Clinical Fellow. This work was supported in part by grants held by the University of Oxford (PI - Helen McShane) from the Wellcome Trust and European Commission.

\section{Author details}

${ }^{1}$ The Jenner Institute, University of Oxford, Oxford, UK. ${ }^{2}$ Present address: Department of Neuroinflammation, Institute of Experimental Immunology, University of Zurich, Zurich, Switzerland. ${ }^{3}$ Present address: Royal Sussex County Hospital, Eastern road, Brighton, UK. ${ }^{4}$ Present address: Centre for Infection, Immunity and Disease Mechanisms, Biosciences, School of Health Sciences and Social Care, Brunel University, Middlesex, UK. ${ }^{5}$ Structural Genomics Consortium, University of Oxford, Oxford, UK. ${ }^{6}$ Cambridge University Hospitals NHS Foundation Trust, Cambridge, UK. ${ }^{7}$ South African Tuberculosis Vaccine Initiative, Institute of Infectious Disease and Molecular Medicine and School of Child and Adolescent Health, University of Cape Town, Cape Town, South Africa. ${ }^{8}$ Present address: London School of Hygiene and Tropical Medicine, Keppel Street, London, UK. ${ }^{9}$ Vaccines for Africa Initiative, Cape Town, South Africa. ${ }^{10}$ Division of Community Health, Stellenbosch University, Stellenbosch, South Africa. ${ }^{11}$ Metropolitan District Health Services, Western Cape, Government: Health, Cape Town, South Africa.

Received: 17 April 2014 Accepted: 24 November 2014 Published online: 03 December 2014

\section{References}

1. WHO Global Tuberculosis Report 2012 [http://www.who.int/tb/ publications/global_report/en/index.html]

2. Rodrigues LC, Diwan VK, Wheeler JG: Protective effect of BCG against tuberculous meningitis and miliary tuberculosis: a meta-analysis. Int $J$ Epidemiol 1993, 22(6):1154-1158.

3. Trunz BB, Fine P, Dye C: Effect of BCG vaccination on childhood tuberculous meningitis and miliary tuberculosis worldwide: a meta-analysis and assessment of cost-effectiveness. Lancet 2006, 367(9517):1173-1180.

4. Colditz GA, Brewer TF, Berkey CS, Wilson ME, Burdick E, Fineberg HV Mosteller F: Efficacy of BCG vaccine in the prevention of tuberculosis. Meta-analysis of the published literature. JAMA 1994, 271(9):698-702.

5. Levine MM: Enteric infections and the vaccines to counter them: future directions. Vaccine 2006, 24(18):3865-3873.

6. Pinder $M$, Reece $W H$, Plebanski $M$, Akinwunmi $P$, Flanagan $K L$, Lee $E A$, Doherty T, Milligan P, Jaye A, Tornieporth N, Ballou R, McAdam KP, Cohen J, Hill AV: Cellular immunity induced by the recombinant Plasmodium falciparum malaria vaccine, RTS, S/ASO2, in semi-immune adults in The Gambia. Clin Exp Immunol 2004, 135(2):286-293.

7. Hallander HO, Paniagua M, Espinoza F, Askelof P, Corrales E, Ringman M, Storsaeter J: Calibrated serological techniques demonstrate significant different serum response rates to an oral killed cholera vaccine between Swedish and Nicaraguan children. Vaccine 2002, 21(1-2):138-145.
8. Hawkridge T, Scriba TJ, Gelderbloem S, Smit E, Tameris M, Moyo S, Lang T, Veldsman A, Hatherill M, Merwe L, Fletcher HA, Mahomed H, Hill AV, Hanekom WA, Hussey GD, McShane H: Safety and immunogenicity of a new tuberculosis vaccine, MVA85A, in healthy adults in South Africa. $J$ Infect Dis 2008, 198(4):544-552.

9. McShane H, Pathan AA, Sander CR, Keating SM, Gilbert SC, Huygen K, Fletcher HA, Hill AV: Recombinant modified vaccinia virus Ankara expressing antigen 85A boosts BCG-primed and naturally acquired antimycobacterial immunity in humans. Nat Med 2004, 10(11):1240-1244.

10. Scriba TJ, Tameris M, Smit E, van der Merwe L, Hughes EJ, Kadira B, Mauff K, Moyo S, Brittain N, Lawrie A, Mulenga H, de Kock M, Makhethe L, Janse van Rensburg E, Gelderbloem S, Veldsman A, Hatherill M, Geldenhuys H, Hill AV, Hawkridge A, Hussey GD, Hanekom WA, McShane H, Mahomed H: A phase lla trial of the new tuberculosis vaccine, MVA85A, in HIV- and/or Mycobacterium tuberculosis-infected adults. Am J Respir Crit Care Med 2012, 185(7):769-778.

11. Tameris MD, Hatherill M, Landry BS, Scriba TJ, Snowden MA, Lockhart S, Shea JE, McClain JB, Hussey GD, Hanekom WA, McShane, MVA85A 020 Trial Study Team: Safety and efficacy of MVA85A, a new tuberculosis vaccine, in infants previously vaccinated with BCG: a randomised, placebocontrolled phase 2b trial. Lancet 2013, 381(9871):1021-1028.

12. Shimizu T, Nomiyama S, Hirata F, Hayaishi O: Indoleamine 2,3-dioxygenase. Purification and some properties. J Biol Chem 1978, 253(13):4700-4706.

13. Yamazaki F, Kuroiwa T, Takikawa O, Kido R: Human indolylamine 2,3dioxygenase. Its tissue distribution, and characterization of the placental enzyme. Biochem J 1985, 230(3):635-638.

14. Mellor AL, Munn DH: IDO expression by dendritic cells: tolerance and tryptophan catabolism. Nat Rev Immunol 2004, 4(10):762-774.

15. Desvignes L, Ernst JD: Interferon-gamma-responsive nonhematopoietic cells regulate the immune response to Mycobacterium tuberculosis. Immunity 2009, 31(6):974-985.

16. Munn DH, Zhou M, Attwood JT, Bondarev I, Conway SJ, Marshall B, Brown C, Mellor AL: Prevention of allogeneic fetal rejection by tryptophan catabolism. Science 1998, 281(5380):1191-1193.

17. Munn DH, Shafizadeh E, Attwood JT, Bondarev I, Pashine A, Mellor AL: Inhibition of T cell proliferation by macrophage tryptophan catabolism. J Exp Med 1999, 189(9):1363-1372.

18. Lee GK, Park HJ, Macleod M, Chandler P, Munn DH, Mellor AL: Tryptophan deprivation sensitizes activated T cells to apoptosis prior to cell division. Immunology 2002, 107(4):452-460.

19. Fallarino F, Grohmann U, You S, McGrath BC, Cavener DR, Vacca C, Orabona C, Bianchi R, Belladonna ML, Volpi C, Fioretti MC, Puccetti P: Tryptophan catabolism generates autoimmune-preventive regulatory T cells. Transp/ Immunol 2006, 17(1):58-60.

20. Frumento G, Rotondo R, Tonetti M, Damonte G, Benatti U, Ferrara GB: Tryptophan-derived catabolites are responsible for inhibition of $\mathrm{T}$ and natural killer cell proliferation induced by indoleamine 2,3-dioxygenase. $J$ Exp Med 2002, 196(4):459-468.

21. Almeida AS, Lago PM, Boechat N, Huard RC, Lazzarini LC, Santos AR, Nociari M, Zhu H, Perez-Sweeney BM, Bang H, Ni Q, Huang J, Gibson AL, Flores VC, Pecanha LR, Kritski AL, Lapa e Silva JR, Ho JL: Tuberculosis is associated with a down-modulatory lung immune response that impairs Th1-type immunity. J Immunol 2009, 183(1):718-731.

22. Suzuki Y, Suda T, Asada K, Miwa S, Suzuki M, Fujie M, Furuhashi K, Nakamura $Y$, Inui N, Shirai T, Hayakawa H, Nakamura H, Chida K: Serum indoleamine 2,3-dioxygenase activity predicts prognosis of pulmonary tuberculosis. Clin Vaccine Immunol 2012, 19(3):436-442.

23. Popov A, Abdullah Z, Wickenhauser C, Saric T, Driesen J, Hanisch FG, Domann E, Raven EL, Dehus O, Hermann C, Eggle D, Debey S, Chakraborty $\mathrm{T}$, Kronke M, Utermohlen O, Schultze JL: Indoleamine 2,3-dioxygenaseexpressing dendritic cells form suppurative granulomas following Listeria monocytogenes infection. J Clin Invest 2006, 116(12):3160-3170.

24. Moreau M, Lestage J, Verrier D, Mormede C, Kelley KW, Dantzer R, Castanon N: Bacille Calmette-Guerin inoculation induces chronic activation of peripheral and brain indoleamine 2,3-dioxygenase in mice. J Infect Dis 2005, 192(3):537-544.

25. Pathan AA, Minassian AM, Sander CR, Rowland R, Porter DW, Poulton ID, Hill AV, Fletcher HA, McShane $\mathrm{H}$ : Effect of vaccine dose on the safety and immunogenicity of a candidate TB vaccine, MVA85A, in BCG vaccinated UK adults. Vaccine 2012, 30(38):5616-5624.

26. Sander CR, Pathan AA, Beveridge NE, Poulton I, Minassian A, Alder N, Van Wijgerden J, Hill AV, Gleeson FV, Davies RJ, Pasvol G, McShane H: Safety 
and immunogenicity of a new tuberculosis vaccine, MVA85A, in Mycobacterium tuberculosis-infected individuals. Am J Respir Crit Care Med 2009, 179(8):724-733.

27. Matsumiya M, Stylianou E, Griffiths K, Lang Z, Meyer J, Harris SA, Rowland R, Minassian AM, Pathan AA, Fletcher H, McShane H: Roles for Treg Expansion and HMGB1 Signaling through the TLR1-2-6 Axis in Determining the Magnitude of the Antigen-Specific Immune Response to MVA85A. PLOS ONE 2013, 8(7):e67922.

28. de Cassan SC, Pathan AA, Sander CR, Minassian A, Rowland R, Hill AV, McShane $\mathrm{H}$, Fletcher HA: Investigating the induction of vaccine-induced Th17 and regulatory T cells in healthy, Mycobacterium bovis BCGimmunized adults vaccinated with a new tuberculosis vaccine, MVA85A. Clin Vaccine Immunol 2010, 17(7):1066-1073.

29. Fletcher HA, Pathan AA, Berthoud TK, Dunachie SJ, Whelan KT, Alder NC, Sander CR, Hill AV, McShane H: Boosting BCG vaccination with MVA85A down-regulates the immunoregulatory cytokine TGF-beta1. Vaccine 2008, 26(41):5269-5275.

30. Muyanja E, Ssemaganda A, Ngauv P, Cubas R, Perrin H, Srinivasan D, Canderan G, Lawson B, Kopycinski J, Graham AS, Rowe DK, Smith MJ, Isern S, Michael S, Silvestri G, Vanderford TH, Castro E, Pantaleo G, Singer J, Gillmour J, Kiwanuka N, Nanvubya A, Schmidt C, Birungi J, Cox J, Haddad EK, Kaleebu P, Fast P, Sekaly RP, Trautmann L: Immune activation alters cellular and humoral responses to yellow fever 17D vaccine. J Clin Invest 2014, 124(7):3147-3158.

31. Ben-Smith A, Gorak-Stolinska P, Floyd S, Weir RE, Lalor MK, Mvula H, Crampin AC, Wallace D, Beverley PC, Fine PE, Dockrell HM: Differences between naive and memory T cell phenotype in Malawian and UK adolescents: a role for Cytomegalovirus? BMC Infect Dis 2008, 8:139.

32. Beveridge NE, Price DA, Casazza JP, Pathan AA, Sander CR, Asher TE, Ambrozak DR, Precopio ML, Scheinberg P, Alder NC, Roederer M, Koup RA, Douek DC, Hill AV, McShane H: Immunisation with BCG and recombinant MVA85A induces long-lasting, polyfunctional Mycobacterium tuberculosis-specific CD4+ memory T lymphocyte populations. Eur J Immunol 2007, 37(11):3089-3100.

33. Huang L, Li L, Klonowski KD, Tompkins SM, Tripp RA, Mellor AL: Induction and role of indoleamine 2,3 dioxygenase in mouse models of influenza a virus infection. PLOS ONE 2013, 8(6):e66546.

34. Sorensen RB, Hadrup SR, Svane IM, Hjortso MC, Thor Straten P, Andersen $\mathrm{MH}$ : Indoleamine 2,3-dioxygenase specific, cytotoxic T cells as immune regulators. Blood 2011, 117(7):2200-2210.

35. Blache CA, Manuel ER, Kaltcheva TI, Wong AN, Ellenhorn JD, Blazar BR, Diamond DJ: Systemic delivery of Salmonella typhimurium transformed with IDO shRNA enhances intratumoral vector colonization and suppresses tumor growth. Cancer Res 2012, 72(24):6447-6456.

doi:10.1186/s12879-014-0660-7

Cite this article as: Tanner et al: Serum indoleamine 2,3-dioxygenase activity is associated with reduced immunogenicity following vaccination with MVA85A. BMC Infectious Diseases 2014 14:660.

\section{Submit your next manuscript to BioMed Central and take full advantage of:}

- Convenient online submission

- Thorough peer review

- No space constraints or color figure charges

- Immediate publication on acceptance

- Inclusion in PubMed, CAS, Scopus and Google Scholar

- Research which is freely available for redistribution

Submit your manuscript at www.biomedcentral.com/submit 